\title{
Study on the Risk Evaluation of Government Purchasing Public Service Based on Matter Element Extension Model
}

\author{
Yanfang Chen \\ College of Economics and Administration, Nanjing University of Aeronautics and Astronautics, Nanjing, China \\ Email: chenyanfang326@163.com
}

How to cite this paper: Chen, Y.F. (2018) Study on the Risk Evaluation of Government Purchasing Public Service Based on Matter Element Extension Model. Open Journal of Social Sciences, 6, 127-143. https://doi.org/10.4236/jss.2018.62012

Received: January 2, 2018

Accepted: February 23, 2018

Published: February 26, 2018

Copyright $\odot 2018$ by author and Scientific Research Publishing Inc. This work is licensed under the Creative Commons Attribution International License (CC BY 4.0).

http://creativecommons.org/licenses/by/4.0/

\begin{abstract}
The government purchase public service has the dual effect of performance and risk, and risk management should run through the purchase service. By identifying the key influencing factors, this paper constructs the risk evaluation index system of government purchasing public services, and introduces the matter element extension method to quantify all kinds of risks. The empirical test is based on the sample data of $S$ province. The results show that the risk level of government purchase of public service is "high" and the trend of "medium" level is obvious. The institutional arrangement leads to a "higher" social risk, management risk and economic risk. It is mainly related to the factors such as voluntary failure, internal effect, social trust, power capital, information disclosure, rules and regulations, and management process. Based on this, this paper puts forward the corresponding policy recommendations.
\end{abstract}

\section{Keywords}

Government Purchase of Public Service, Risk Identification, Matter-Dollar Extension, Risk Prevention

\section{Introduction}

The risk of government buying public service is the loss that may arise from the government's purchase of public services, which is the distance between the desired goals and the actual results. Based on the public service administrative monopoly supply model to reflect the economic cost, social benefits and public value, in the new public management movement background, our country and western countries in practice, changed the public service supply system, pushing government purchase of public service system. In the deployment of the gov- 
ernment, the government purchase of public services into the normal development and improvement in the quality of public services ease the financial pressure, and improve the image of the government achieved remarkable results. However, with the promotion of the system, many problems also follow. During the process of government purchase of public services, a lot of purchasing chaos has led to serious waste of public resources, lack of publicity, public discontent. Institutional arrangements did not achieve the desired results, and the implementation of the system in the course of the abnormal situation led to people's rational thinking. Although the purpose of the government's purchase of public services is to achieve the market-oriented allocation of public resources, as a new system, under the circumstances of lack of practice and knowledge, there is a great deal of uncertainty risk in the way of "exploring and advancing". At present, there is a certain relationship between the exposed problems and the lack of awareness of institutional arrangements, risk prevention and control is not in place. Therefore, in order to further improve the performance of the system arrangement and reduce the risk of system operation, it is necessary to further explore the risk of government procurement of public services, and put forward effective risk prevention countermeasures.

\section{Overview of the Digest Format}

Overseas research on government procurement of public services risk factors started earlier, more systematic and comprehensive. Opponents argue that the government purchase of public services is short-sighted, irresponsible and extravagant [1], the existence of "competition" veil of fantasy [2], will trigger a "privatization crisis" [3]. The main factors are: purchase pattern [4], market transaction cost [5], Contract management complexity [6], market construction [7], citizen participation [8], The nature of public services [9], Regulation and government supervision of cost [10], The ability of the government contract management) [11], Institutional environment [12], "Supply side defects" and "demand side defects" [13], Geographical region [14], Market characteristics, citizen characteristics and regional characteristics [15] etc.

Different from foreign studies, there are not many literatures about the risk factors of public service purchase in China, and the relevant discussions are mainly scattered in the analysis of relevant issues and policy recommendations. Roughly divided into three directions: First, the purchase of public services in government management, involving regulations, functions, boundaries, management processes. In the purchase of public service should bear the unshrinkable responsibility of public management responsibilities, clear boundary [16], define the scope of the purchase of public services and the bottom line [17], the construction of legal system [18], perfect management institution, supervision mechanism and management mechanism to undertake the mechanism [19]. Two is the purchase of public services in the maintenance of the market, including the nature of the market, the operating mechanism, the way to buy more 
discussed. The government purchase of public services is actually created a quasi-market [20], facing the demand side and supply defects [21], strengthening contract management is the risk prevention of the road [22]. Three is the purchase of public service in social interaction, mainly related to autonomy, participation and cooperation. The government purchase of services is an important way for the government and non-profit organizations to build partnerships [23], transfer and undertake are two important mechanisms in the process of purchasing [24], remodeling of multi subject cooperation governance network [25], the establishment of multi subject distribution and risk sharing mechanism is the core of risk prevention [26].

Through the literature review found that domestic and foreign government procurement of public service risk research is very different, fully confirms the current public management of "environment is important" argument attention and emphasis. Foreign research is more mature, and more empirical methods are adopted, emphasizing market competition and government management. Although after the peak development in 90s, the government has paid more attention to the purchase of public services, but its rich research results can provide a good reference and reference. However, domestic scholars mostly use theoretical research, pay attention to "how to buy", and discuss less about risk. Although the existing research results can also explain the cause of the risk, but lack of systematic combing and empirical test, it is difficult to judge the status and importance of the risk, and the actual operation is not good enough. Based on the above considerations, this paper intends to buy the government public service risk problem research, risk identification and the key influence factors, using mathematical models to measure, through the risk probability, risk intensity and key risk factors to define risk.

This paper attempts to enrich the existing literature in the following three aspects: first, from the research point of view, different from the current problems existing countermeasures, based on the view of risk, through the risk analysis of the influencing factors, basic path and mechanism in defining risk, explain the formation of an integrative framework; second, from the research methods the mathematical model, risk measure, can make up for a single defect theoretical analysis as the main research method, which combines qualitative and quantitative interpretation of verification; third, from the expected results, to obtain quantitative data on the risk status and the important degree, contribute to the key elements of screening to enhance the actual operability.

\section{Risk Evaluation Index System about Government Purchasing Public Service}

Government purchasing public service risk is a complex problem with multiple angles, levels and factors. An ordered hierarchical structure model can decompose complex problems step by step according to the governing relationship. According to this, various risk factors are judged, classified and collate, and a 
hierarchical structure model about the risk assessment of government purchase of public services is constructed. In this model, the government purchase of public service risk is the target, according to public resources, intermediate production conversion, public service output and feedback of the basic processes, the general aim is decomposed into economic risk, market risk, social risk and risk management, as the rule layer, which is the first level evaluation index. Then, according to the path and mechanism of risk generation, we select and identify the key factors from the constraints of situation, action logic and technology operation as the index level, that is, the second level evaluation index. Finally, 4 first grade evaluation indexes and 20 two grade evaluation indexes are determined to form a systematic and complete hierarchy evaluation index system (as shown in Table 1).

\subsection{Economic Risk}

The economic benefits of government buying public services mainly come from two aspects: the supply of private capital to state capital and the structural optimization of public expenditure. The phenomenon of "economic paradox" in practice is related to the factors of regional heterogeneity, public budget, internal effect, power capital and transaction cost.

Regional heterogeneity refers to the difference of natural endowments among different regions, such as natural, economic, humanistic and social factors. It emphasizes the constraint space of resource acquisition and allocation. With the opening of the public resource allocation system, the conflict between the limitation of resources and the infinity of demand and the strong impulse of resource acquisition by the actors make any institutional arrangement likely to produce instrumentalism tendency.

Doing well budgetary fund arrangement, standardizing the financial appropriation and transfer payment is the premise and guarantee for controlling the government's fiscal expenditure and improving the efficiency of fund allocation. According to the notice on the budget management of government procurement services, the funds required by the government to purchase services should be included in the budget, and adhere to the principle of "non-budget not implemented" and "budget after implementation" principle. However, in Chinese fiscal decentralization and political centralization system, due to the lack of budget mechanism, soft constraint, no budget constraint problem, public finance change as a strategic tool, the expenditure structure is distorted seriously.

The "internal effect" refers to the phenomenon that the government departments seek private interests rather than public interests, emphasizing the self-interest and limited rationality of the government departments. Have greater discretion in the non-compulsory administration within the scope of the local government, in order to finance income and private income maximization, borrow "government purchase" in the name of misappropriating cash, forming "organized irresponsibility" situation. 
Table 1. Government purchase public service risk evaluation index system.

\begin{tabular}{|c|c|c|}
\hline First level index & Second level index & Definition of indicators \\
\hline \multirow{5}{*}{ Economic risk } & $\begin{array}{c}\text { Regional } \\
\text { heterogeneity }\end{array}$ & $\begin{array}{l}\text { Regional heterogeneity refers to the difference of natural endowments among different regions, } \\
\text { such as natural, economic, humanistic and social factors. }\end{array}$ \\
\hline & $\begin{array}{l}\text { Public finance } \\
\text { budget }\end{array}$ & $\begin{array}{l}\text { The public budget revenue means that the government raises the revenue of the tax as the main } \\
\text { body by means of the national political power and social management. }\end{array}$ \\
\hline & Internal effect & $\begin{array}{l}\text { The "internal effect" refers to the phenomenon that the government departments seek private } \\
\text { interests rather than public interests, emphasizing the self-interest and limited rationality of the } \\
\text { government departments. }\end{array}$ \\
\hline & power capital & $\begin{array}{l}\text { "Power capitalization" refers to the act of obtaining political privileges by using the public power } \\
\text { of the government and the economic activities of the capital, so as to seek the unfair additional } \\
\text { interests or monopoly interests of individuals or groups. }\end{array}$ \\
\hline & transaction cost & $\begin{array}{l}\text { Transaction cost refers to the cost that people have to pay voluntarily and cooperate with each } \\
\text { other in a certain social relationship, which corresponds to the "production cost". }\end{array}$ \\
\hline \multirow{4}{*}{ Market risk } & $\begin{array}{l}\text { Quasi market } \\
\text { mechanism }\end{array}$ & $\begin{array}{l}\text { Quasi market mechanism is a form of intermediate between Bureaucracy and free market, which } \\
\text { is built by the government and introduced into competition in the field of public service. }\end{array}$ \\
\hline & $\begin{array}{l}\text { Market access } \\
\text { standards }\end{array}$ & $\begin{array}{l}\text { Market access standards generally refer to the extent to which goods, labor and capital are allowed } \\
\text { to compete in the market. }\end{array}$ \\
\hline & $\begin{array}{l}\text { Incomplete } \\
\text { contracts }\end{array}$ & $\begin{array}{l}\text { Incomplete contract means that the contracting parties cannot fully foresee various situations that } \\
\text { may arise in the performance period, so that a complete and detailed contract clause cannot be } \\
\text { achieved. }\end{array}$ \\
\hline & Market defects & $\begin{array}{l}\text { Market defect means that the market mechanism alone cannot reach the optimal allocation state } \\
\text { of resources. }\end{array}$ \\
\hline \multirow{4}{*}{ Social risk } & Institutional change & $\begin{array}{l}\text { Institutional change refers to the dynamic process of the new system (or new institutional } \\
\text { structure) producing, replacing or changing the old system. }\end{array}$ \\
\hline & Voluntary failure & $\begin{array}{l}\text { Voluntary failure refers to the phenomenon that voluntary or non-governmental organizations or } \\
\text { individuals are experiencing various problems in their volunteer activities, which makes volunteer } \\
\text { activities unable to perform normally. }\end{array}$ \\
\hline & Social trust & $\begin{array}{l}\text { Social trust mainly refers to a set of universally similar attitudes towards social activities or } \\
\text { institutions such as public affairs, public organizations, interpersonal relationships and other } \\
\text { social members. }\end{array}$ \\
\hline & $\begin{array}{l}\text { Cooperation } \\
\text { mechanism }\end{array}$ & $\begin{array}{l}\text { Cooperation is a joint action and way of cooperation between individuals and individuals, groups } \\
\text { and groups in order to achieve common purposes. The basic conditions of cooperation are } \\
\text { consistent goals, unified understanding and norms, mutual trust of cooperation atmosphere and } \\
\text { certain material basis for cooperation to exist and develop. }\end{array}$ \\
\hline \multirow{3}{*}{$\begin{array}{l}\text { Management } \\
\text { risk }\end{array}$} & Quality of managers & $\begin{array}{l}\text { The chief executive's quality is mainly embodied in political accomplishment, professional ability, } \\
\text { leadership ability, moral quality and so on, which directly affects the government's management } \\
\text { ability. }\end{array}$ \\
\hline & Management Agency & $\begin{array}{l}\text { Refers to the administrative organs in accordance with the provisions of the Constitution and } \\
\text { other relevant laws, in accordance with certain procedures set up, exercising national } \\
\text { administrative power, which perform various administrative functions of the state organs, } \\
\text { is an important part of national institutions, also known as administrative organs, government } \\
\text { agencies etc. }\end{array}$ \\
\hline & Institutional norms & $\begin{array}{l}\text { The Institutional norm is a general term for all rules and regulations, regulations, rules, } \\
\text { procedures, standards, and methods to restrict the behavior of all members in the process of } \\
\text { organization management. }\end{array}$ \\
\hline
\end{tabular}


The administrative decision of administrative organs to the national staff in the State Administration, in order to achieve the desired goals under certain circumstances and conditions,

Decision mechanism the use of scientific theories and methods, systematically analyzes the subjective and objective conditions, in addition to a large number of relevant information on the problems to be solved or the business process make a decision.

Supervision and restriction mechanism

Performance evaluation mechanism
Administrative supervision refers to the specific administrative act of the state administrative organ and other administrative bodies to see and understand and master their obligations and fulfill obligations according to the organizations and individuals who have the obligation to carry out and abide by the relevant administrative regulations, administrative instructions, orders and decisions.

Administrative performance evaluation is to collect, organize, summarize and summarize administrative performance information based on scientific and objective methods, standards and procedures, and conduct overall assessment activities on this basis, also known as administrative performance appraisal.

"Power capitalization" refers to the act of obtaining political privileges by using the public power of the government and the economic activities of the capital, so as to seek the unfair additional interests or monopoly interests of individuals or groups. When a large number of private capital enters the public service field, power is easily linked with capital. In the case of bureaucratic monopoly capital, enterprise capture of government and related party transactions, social welfare is to exploit and plunder and government procurement of public services has become a tool for a small number of people to seek private benefits.

Transaction cost refers to the cost that people have to pay voluntarily and cooperate with each other in a certain social relationship, which corresponds to the "production cost". Any institutional arrangements are not abstract the existence of transaction costs in the government behavior widely exists and cannot disappear [27]. Information cost, decision cost, negotiation cost, supervision cost, risk cost and so on belong to the category of transaction cost. The impact of transaction costs on organizational behavior is an important factor to avoid the "ceiling" of decision enforcement.

\subsection{Market Risk}

When public service transfers from hierarchical direct production to market-oriented institutional arrangement, the result is complex and multiple. In the context of government purchase of public services, market risks are mainly characterized by supply blindness, lack of supply, lack of publicity, external negative effects, etc., mainly related to quasi market mechanism, market access barriers, incomplete contracts and market defects.

The public service market is not a product of the evolution and segmentation of the free market, but a quasi-market formed by the government led by the introduction of competition mechanism in the field of public service, an intermediate form between Bureaucracy and free market. Compared to the free market, uncertainty and competitive inadequacy are the two major challenges it faces. 
The decision on "want to buy" and "buy what" depends on the multiple factors such as administrative preference, social acceptance, public demand, ideology and so on. Moreover, the existence of "demand side defect" and "supply side defect" also decide that the quasi market of government buying public services cannot be a sufficient competition, and it is difficult to fulfill the promise of efficiency.

The admittance standard is one of the key factors that affect the market structure and the level of competition. As the country takes the development of social organization into the important category of social governance innovation, the obstacles of social organization in policy and system are gradually removed. However, behind the seemingly relaxed policy environment, social organizations have encountered hidden access barriers such as "regulation formalism", "glass door", "spring door" and so on. Especially the typical administrative barriers such as "internal fixed", tailored qualification requirements, and intra institutional cooperation have shut out some good social organizations without background. The public service market built by the government has been locked into the internal locking state. The unequal opportunity for competitive opportunity also increases the space for rent-seeking corruption at the same time as it weakens the competitiveness.

Contract outsourcing refers to the government's contract and contract with the eligible participants according to the nature and characteristics of the project, so as to clarify the rights and obligations of both sides. It is the dominant form of the government to buy public services. Because of limited rationality, market information asymmetry and transaction complexity, the contract is used to limit speculation or motivation contract becomes the incomplete contract, which happens to the imperfection in management loopholes or defects, opportunistic behavior likely to cause the action of the main body, moral hazard and adverse selection.

Market defects show that there is a border in the market-oriented reform. As the "government purchase service" has been studied for longer and more fields, it is found that the market does not always bring cost savings, efficiency improvement, and quality improvement. Even if the marketization can realize the optimal allocation of resources, it cannot eliminate the public value crisis and negative external effect. As Richard Blunck said: "the free market this invisible hand, although it cannot doubt the power, but it is still not enough to ensure that many involved human happiness, and can achieve social goals for human progress to optimism".

\subsection{Social Risk}

Government procurement of public services has the characteristics of multi objective attributes, in addition to cost savings, competitive efficiency and other economic benefits, but also takes into account social governance, public response, fairness and justice and other social benefits. Government purchase of 
public services as an authoritative redistribution of public interest has the possibility of causing social order disorder, conflict and even social crisis, mainly related to institutional change, voluntary failure, social trust, cooperation mechanism, information disclosure and other factors.

As a new institutional supply under the reform of public service system, the government purchases public services, or rather a system change from top to bottom with the authority of the government. The limitation of the system is that the institutional arrangement is not a natural endogenous result on the basis of the repeated game of the stakeholders. First, when the institutional arrangements are not matched with the institutional environment, the policy will distort and even fail. Secondly, the institutional change is centered on the reconstruction of interests, and the resistance and resistance of the damaged parties may lead to new social contradictions. In addition, there is a "policy gap" defect in the institutional change in the short term, which can easily induce strategic behavior.

The phenomenon that voluntary organizations are trapped inside and outside the organization cannot effectively engage in voluntary service is voluntary failure. Because of its organizational, professional, nonprofit, folk and voluntary advantages, social organization has become the most important actor in the power of public service. However, for a long time, due to social system, growth path, self-development and ideology and other factors, social organization's living space is narrow, its main body status and volunteer function are missing. In the aspects of independence, autonomy, professionalism and credibility, it is obvious that it is unable to undertake the social functions effectively, and has become a short board for the governance of social cooperation.

Social trust is not only a psychological contract and social capital, but also a beneficial supplement to the formal system of social governance, which can better maintain the governance network [28]. But as far as our government is concerned with the purchase of public services, lack of trust has become a difficult problem. The deep-rooted traditional ideas and public cognitive bias make the institutional arrangement a challenge to the credibility of the system itself. Coupled with the weakness of public service, weak market evaluation, bureaucratic closeness, inadequate government response and public opinion management, there is a lack of positive interaction between the government and the public. In addition, the large purchase failure in recent years has seriously frustrated public confidence.

In the perspective of social governance, "government purchase of public service" is the transfer of public service function through the cooperation of the government and the society. Up to now, the prototype of the multi-agent cooperative governance network has come into being. However, the relationship between network organization and synergy is not a simple linear relationship, and the network organization is not naturally capable of producing synergies. The development and development of cooperation requires high autonomy and de- 
pendence between the two sides. Different objects, choose cooperation constraints, and resource dependence favoritism are likely to lead to "cooperation failure" [29].

Information disclosure belongs to the category of procedural norms. It is the premise and foundation of information communication, which can effectively prevent non-public application of public power and guarantee fair competition and informed supervision. According to the world trade organization to develop the "government procurement agreement", in the procurement of information release, the procurement notice, the participation conditions, supplier qualification, technical specifications, tender documents, term, negotiation, restricted electronic bidding, quotation, tender and contract award and other aspects of the information and requirements must be comprehensive and detailed publicity [30].

\subsection{Management Risk}

Only the government is responsible, "government procurement of public services" can be responsible [31]. The government by direct payment to the guarantor does not mean escape the responsibility of the government in the field of public service. On the contrary, the government should take the administrative responsibility guarantee [32]. Management risk is mainly related to the quality of managers, organizational structure, system construction and management process.

The quality of the administrators is embodied in the aspects of political accomplishment, professional ability, leadership ability and moral quality, which directly affect the government's management ability. In practice, many government officials disapprove of the government's purchase of public services, and regard them as "tools of political tournaments" and "strategic arrangements for emotional care". In addition, the high incidence of bribery, rent-seeking, corruption and other problems are not related to the quality of the managers.

The construction of government management ability should strengthen the organization guarantee. At present, China's government purchase of public service management institutions are mainly functions department management, special committees, the respective functions of management and management combined with four modes, but the presence of repetition, lack of unified and professional, and the demand for public services do not match the problem [33], seriously affected the government purchases of public services unified deployment and supervision and management work.

The system is the boundary, the bottom line and the basis of action. Although the "government purchase of public service" has been in practice for more than ten years, it still faces the dilemma of "lack of policy and system". The lack of system supply, design defects, rigid operation, lack of repair capacity and other reasons led to the lack of legal support and necessary constraints for the government to purchase public services. There are institutional gaps or gray areas are often unspoken rule in space, there is dereliction of duty, money transaction risk.

Decision-making ability is the core ability of modern government manage- 
ment. Lack of public participation, the black box operation and authoritarian leaders are typical manifestations of our government decision-making ineffective. It is mainly related to the excessive concentration of administrative decision-making power and the excessive scope of discretion in china. One of the results of public service outsourcing is a decentralized decision making [34].

Not to abuse administrative power must accept supervision, which is law. The actual management is faced with the dilemma of supervision "weakening" and "deficiency". It shows that the supervision is formalized, the supervision subject is scattered, the scope of supervision is limited, the supervision mode is rigid, the responsibility is not implemented, and the supervision mode is lagging behind. Government management has fallen into "internal unconstrained and external non control" deadlock, and the quality of public services cannot be guaranteed.

Government performance evaluation is a kind of preventive risk filtering mechanism, although the government performance evaluation concept has been widely recognized in recent years, but the actual progress is relatively slow. On the one hand, the intangible, heterogeneous and perishable characteristics of the evaluation object make it difficult to obtain and evaluate the information. On the other hand, the problems such as formalization of assessment, serious internal control, and disconnection between evaluation and feedback restrict the effectiveness of performance evaluation mechanism.

\section{Risk Evaluation of Government Purchasing Public Service Based on Matter Element Extension}

The extension evaluation method is one of the main application of extenics, including basic element theory, extension set theory and extension logic as the foundation, through the matter-element model to describe the characteristics of things, to make quantitative analysis of extension set theory and dependent function theory, and combining with the dynamic management system, identify the key indicators of greater risk the [35]. At present, this method is widely used, involving engineering, humanities, social sciences and other disciplines. According to the above factors, the government purchase of public service risk with integrated features and the complexity and diversity, especially in the current highly open environment showed more uncertainty, fuzzy and dynamic significant risk, easy to upgrade transformation. The method of matter-element extension evaluation is based on Modeling and combining qualitative and quantitative methods to deal with the contradictory problems under the complex influence of many factors. The logic of research is highly consistent with the problems under discussion. Therefore, it is more appropriate to select the matter-element extension method to evaluate the factors that affect the government's public service risk.

\subsection{Constructing a Matter-Element Extension Evaluation Model of Government Purchasing Public Service Risk}

1) Constructing matter-element matrix. Matter element, as a logical cell of ex- 
tenics, is an ordered three tuple composed of the characteristic of a thing $N$ and its quantity value $V, R=$ (things, characteristics, values) $=(N, c, V)$.

To evaluate the $\mathrm{N}$ government's purchase of public service risk, the characteristic value $c_{1}, c_{2}, \cdots, c_{n}$ and its corresponding quantity value $v_{1}, v_{2}, \cdots, v_{n}$ can be described

$$
R=\left[\begin{array}{c}
R_{1} \\
R_{2} \\
\vdots \\
R_{n}
\end{array}\right]=\left[\begin{array}{ccc}
N & C_{1} & v_{1} \\
& C_{2} & v_{2} \\
& \vdots & \vdots \\
& C_{n} & v_{n}
\end{array}\right]
$$

Assuming that the government purchases $n$ index of risk factors for public services, and the risk is divided into $j$ grades, then the formula (2) can be used to represent the classical domain matter matrix.

$$
R_{j}=\left[\begin{array}{ccc}
N_{j} & c_{1 j} & v_{1 j} \\
& c_{2 j} & v_{2 j} \\
\vdots & \vdots \\
& c_{n j} & v_{n j}
\end{array}\right]=\left[\begin{array}{ccc}
N_{j} & c_{1 j} & \left(a_{1 j}, b_{1 j}\right) \\
& c_{2 j} & \left(a_{2 j}, b_{2 j}\right) \\
\vdots & \vdots \\
& c_{n j} & \left(a_{n j}, b_{n j}\right)
\end{array}\right]
$$

If $N_{p}$ represents the government's overall level of public service risk, the $v_{i p}=\left(a_{i p}, b_{i p}\right)$ is the full range of the risk assessment index $c_{i j}$, which is the domain matter matrix, which can be expressed as a formula (3).

$$
R_{P}=\left[\begin{array}{ccc}
N_{p} & c_{1} & v_{p 1} \\
& c_{2} & v_{p 2} \\
\vdots & \vdots \\
& c_{n} & v_{p n}
\end{array}\right]=\left[\begin{array}{ccc}
N_{p} & c_{1} & \left(a_{p 1}, b_{p 1}\right) \\
& c_{2} & \left(a_{p 2}, b_{p 2}\right) \\
\vdots & \vdots \\
& c_{n} & \left(a_{p n}, b_{p n}\right)
\end{array}\right]
$$

2) Calculate association degree. The correlation degree is used to describe the degree of attribution of the risk evaluation index to the evaluation grade. It is usually expressed by correlation function, such as formula (4).

$$
k_{j}\left(v_{i k}\right)=\left\{\begin{array}{l}
\frac{\rho\left(v_{i k}, v_{i k j}\right)}{\rho\left(v_{i k}, v_{i k p}\right)-\rho\left(v_{i k}, v_{i k j}\right)}, \rho\left(v_{i k}, v_{i k p}\right) \neq \rho\left(v_{i k}, v_{i k j}\right) \\
-\rho\left(v_{i k}, v_{i k j}\right), \rho\left(v_{i k}, v_{i k p}\right)=\rho\left(v_{i k}, v_{i k j}\right)
\end{array}\right.
$$

$k_{j}\left(v_{i k}\right)$ represents the correlation function value of the index $c_{i k}$ at the $j$ level, and $\rho\left(v_{i k}, v_{i k j}\right)$ represents the distance between the index and its classical domain, and $\rho\left(v_{i k}, v_{i k p}\right)$ represents the distance between the index $c_{i k}$ and its section field, where $i=1,2, \cdots, n, j=1,2, \cdots, m, \rho\left(v_{i k}, v_{i k j}\right)$ and $\rho\left(v_{i k}, v_{i k p}\right)$ can be calculated by formula (5).

$$
\left\{\begin{array}{l}
\rho\left(v_{i k}, v_{i k j}\right)=\left|v_{i k}-\frac{a_{i j}+b_{i j}}{2}\right|-\frac{b_{i j}-a_{i j}}{2} \\
\rho\left(v_{i k}, v_{i k p}\right)=\left|v_{i k}-\frac{a_{i p}+b_{i p}}{2}\right|-\frac{b_{i p}-a_{i p}}{2}
\end{array}\right.
$$


On this basis, according to the formula (6), we can obtain the correlation degree of the government purchasing public service risk $N$ for the first level index $c_{i}$ about grade $j$.

$$
K_{j}\left(N_{i}\right)=\sum_{i=1}^{n} w_{i} K_{j}\left(v_{i j}\right)
$$

Similarly, according to the formula (7), we can obtain the correlation degree of the government purchasing public service risk $N$ about grade $j$.

$$
K_{j}(N)=\left\{\max K_{j}\left(N_{i}\right)\right\}
$$

3) Rating. It is helpful to judge the degree of risk evaluation index bias to adjacent grade by calculating the characteristic value of risk rank variable $j^{*}$.

$$
\begin{gathered}
\overline{K_{j}(N)}=\left(K_{j}(N)-\min K_{j}(N)\right) /\left(\max K_{j}(N)-\min K_{j}(N)\right) \\
j^{*}=\sum_{j=1}^{m} \overline{j K_{j}(N)} / \sum_{j=1}^{m} \overline{K_{j}(N)}
\end{gathered}
$$

\subsection{The Process of Government Extension Evaluation for Public Service Risk Taking S Province as an Example}

In view of the fact that $S$ is one of the more developed eastern coastal economic province, to carry out the purchase service practice of earlier, larger, buy project categories comprehensive and mature operation mechanism, availability, reliability and capacity of sample space with operational advantages in data. Taking $S$ Province as an example, the investigation is carried out to verify the practicability of the extension evaluation model of government procurement of public service risk. The specific process is as follows:

1) Data collection and processing

For the convenience of data processing, in the investigation before a detailed design of the structure and content of the questionnaire: determine the joint domain range of all kinds of evaluation model that all indicators of the $v_{i p}$ $[0,10]$, divide the risk is low, low, medium, high, high grade range of five, respectively $(0,2),(2,4),(4,6),(6,8),(8,10)$, which is the evaluation index of each evaluation grade of the classical domain $\left(v_{i j}\right)$.Clear investigation objects, including the relevant departments of government staff, social service personnel, experts and community residents. The research contents are strictly carried out in accordance with the risk evaluation index system. A total of 300 questionnaires were sent out, and the invalid questionnaires were deleted. The total number of valid questionnaires was 267 , the effective rate was $89 \%$, and the survey result was $R$. In order to obtain the index weight, this paper follows the expert opinion and uses the analytic hierarchy process to determine the index weight coefficient $(w)$. Finally, the statistical analysis results and weight coefficients are shown in Table 2.

2) Calculate the degree of risk correlation

The greater the degree of association, the greater the likelihood that the risk level belongs to that level. According to the calculation formula of correlation 
degree, we can obtain the correlation degree value and the risk grade of the second grade indexes of the government purchase public service risk at first (Table 3).

Similarly, the degree of relevance of the first level index of government purchase of public service risk on each evaluation grade can be obtained. Details are shown in Table 4.

Finally, the government purchase of public service risk on the evaluation of the evaluation of the degree of relevance. The result of the calculation is shown in Table 5.

\subsection{Risk Assessment Results Analysis}

The calculation results show that $k_{4}(N)=0.010$, based on the maximum membership degree principle, $S$ provincial government purchase of public service risk as the "higher" level, feature level variable value $j^{\wedge *}=3.50$, the actual risk between "medium" and "high level" intermediate state, the overall risk is still in the controllable range.

In the first level index, the market risk is medium, the rank variable characteristic value is $j^{\wedge *}=3.19$, and the risk is smaller to the higher grade. Economic risk, social risk and management risk belong to the category of "higher" level, which is the main result of government purchase of public service risk. All three have space to moderate, but the three have different potentials. According to the eigenvalues of grade variables, social risk into "difficulty slightly medium" level is less than the economic risk and management risk. According to the ranking results of correlation degree, the degree of social risk correlation is obviously higher than that of management risk and economic risk. Then, for the whole risk control, social risk is significant.

Extension evaluation can not only evaluate the overall state of risk, but also evaluate single index, and achieve classification and grading of indicators. This is

Table 2. Risk evaluation index value and weight.

\begin{tabular}{cccccc}
\hline$C_{i j}$ & $\boldsymbol{R}$ & $\boldsymbol{w}_{i j}$ & $C_{i j}$ & $R$ & $w_{i j}$ \\
\hline Regional heterogeneity $C_{11}$ & 5.15 & 0.012 & Institutional change $C_{31}$ & 4.27 & 0.025 \\
Public finance budget $C_{12}$ & 5.38 & 0.018 & Voluntary failure $C_{32}$ & 6.73 & 0.128 \\
$\quad$ Internal effect $C_{13}$ & 6.54 & 0.059 & Social trust $C_{33}$ & 6.46 & 0.082 \\
power capital $C_{14}$ & 6.22 & 0.028 & Cooperation mechanism $C_{34}$ & 5.43 & 0.270 \\
Transaction cost $C_{15}$ & 4.69 & 0.006 & Information disclosure $C_{35}$ & 6.19 & 0.053 \\
Quasi market mechanism $C_{21}$ & 5.31 & 0.032 & Quality of managers $C_{41}$ & 5.13 & 0.022 \\
Market access standards $C_{22}$ & 5.95 & 0.007 & Management Agency $C_{42}$ & 4.38 & 0.009 \\
Incomplete contracts $C_{23}$ & 5.46 & 0.015 & Institutional norms $C_{43}$ & 6.30 & 0.055 \\
Market defects $C_{24}$ & 3.95 & 0.003 & Decision mechanism $C_{44}$ & 6.08 & 0.055 \\
& & & Supervision and restriction mechanism $C_{45}$ & 6.15 & 0.090 \\
& & & Performance evaluation mechanism $C_{46}$ & 5.85 & 0.033 \\
\hline
\end{tabular}


Table 3. Correlation of grade second indicators for each evaluation grade and risk grade.

\begin{tabular}{|c|c|c|c|c|c|c|}
\hline$C_{i j}$ & $k_{1}\left(v_{i j}\right)$ & $k_{2}\left(v_{i j}\right)$ & $k_{3}\left(v_{i j}\right)$ & $k_{4}\left(v_{i j}\right)$ & $k_{5}\left(v_{i j}\right)$ & $j_{0}$ \\
\hline$C_{11}$ & -0.394 & -0.192 & 0.213 & -0.149 & -0.370 & 3 \\
\hline$C_{12}$ & -0.423 & -0.230 & 0.155 & -0.118 & -0.362 & 3 \\
\hline$C_{13}$ & -0.568 & -0.423 & -0.135 & 0.185 & -0.297 & 4 \\
\hline$C_{14}$ & -0.528 & -0.370 & -0.055 & 0.062 & -0.320 & 4 \\
\hline$C_{15}$ & -0.364 & -0.128 & 0.173 & -0.218 & -0.414 & 3 \\
\hline$C_{21}$ & -0.414 & -0.218 & 0.173 & -0.128 & -0.364 & 3 \\
\hline$C_{22}$ & -0.500 & -0.333 & 0.101 & -0.012 & -0.333 & 3 \\
\hline$C_{23}$ & -0.433 & -0.243 & 0.135 & -0.106 & -0.359 & 3 \\
\hline$C_{24}$ & -0.331 & 0.013 & -0.013 & -0.342 & -0.506 & 2 \\
\hline$C_{31}$ & -0.347 & -0.059 & 0.068 & -0.288 & -0.466 & 3 \\
\hline$C_{32}$ & -0.591 & -0.455 & -0.183 & 0.287 & -0.280 & 4 \\
\hline$C_{33}$ & -0.558 & -0.410 & -0.115 & 0.149 & -0.303 & 4 \\
\hline$C_{34}$ & -0.428 & -0.238 & 0.143 & -0.111 & -0.360 & 3 \\
\hline$C_{35}$ & -0.524 & -0.365 & -0.048 & 0.052 & -0.322 & 4 \\
\hline$C_{41}$ & -0.391 & -0.188 & 0.218 & -0.152 & -0.371 & 3 \\
\hline$C_{43}$ & -0.352 & -0.080 & 0.095 & -0.270 & -0.453 & 3 \\
\hline$C_{43}$ & -0.538 & -0.383 & -0.075 & 0.088 & -0.315 & 4 \\
\hline$C_{44}$ & -0.510 & -0.347 & -0.020 & 0.021 & -0.329 & 4 \\
\hline$C_{45}$ & -0.519 & -0.358 & -0.038 & 0.041 & -0.325 & 4 \\
\hline$C_{46}$ & -0.516 & -0.355 & -0.033 & 0.035 & -0.326 & 4 \\
\hline
\end{tabular}

Table 4. The government purchase of public service risk level indicators on the degree of association and the characteristic value of the level variables.

\begin{tabular}{cccccccc}
\hline$C_{i}$ & $k_{1}\left(v_{i}\right)$ & $k_{2}\left(v_{i}\right)$ & $k_{3}\left(v_{i}\right)$ & $k_{4}\left(v_{i}\right)$ & $k_{5}\left(v_{i}\right)$ & $j_{0}$ & $j^{*}$ \\
\hline$C_{1}$ & -0.060 & -0.042 & -0.003 & 0.008 & -0.039 & 4 & 3.56 \\
$C_{2}$ & -0.024 & -0.013 & 0.008 & -0.007 & -0.021 & 3 & 3.19 \\
$C_{3}$ & -0.273 & -0.176 & 0.005 & 0.014 & -0.187 & 4 & 3.48 \\
$C_{4}$ & -0.133 & -0.089 & -0.004 & 0.005 & -0.087 & 4 & 3.52 \\
\hline
\end{tabular}

Table 5. Correlation degree value of public service risk on each evaluation grade.

\begin{tabular}{cccccccc}
\hline$C$ & $k_{1}(N)$ & $k_{2}(N)$ & $k_{3}(N)$ & $k_{4}(N)$ & $k_{5}(N)$ & $j_{0}$ & $j^{*}$ \\
\hline & -0.196 & -0.127 & 0.002 & 0.010 & -0.133 & 4 & 3.50 \\
\hline
\end{tabular}

a great advantage of this method. The index can be classified according to the extension evaluation results of the government purchase of public service risks. Risk handling should be stressed, and corresponding measures can be taken to 
deal with different levels of risk. For the "higher" level of risk indicators, we should take immediate measures to focus on prevention and control. For the "medium" level of risk, we should closely monitor and find out the problems in time.

\section{Conclusion}

This paper puts forward an index system to measure the risk of government purchase of public service, and gives a matter-element extension model to measure the risk of government buying public services. The empirical test results show that the model has a certain practical value. First, it expands the thinking for the government to purchase the risk of public service, and breaks the thinking limitation of the simple qualitative interpretation. Secondly, by using matter-element extension model, correlation function is used to do correlation analysis, so that the importance and function size of each index can be visually quantified, so that precautions against risks are more targeted. But I think it needs to be further improved. First, the government purchase of public service risk is the result of multiple factors, and the selection of the index still needs to be expanded and selected. Second, the extension evaluation method is simple and convenient to operate, and has strong practicability. However, in view of the government purchase of public service risk in this paper, the data acquisition and quantification still needs to be considered. Third, the government's purchase of public services has strong heterogeneity, regionalism and timeliness, which suggests that we can conduct in-depth and horizontal research for different types of services.

\section{References}

[1] Buchheit, B. (2013) 8 Ways Privatization Has Brought Pain and Misery to American life. Alternet.

[2] Keitel, D. (2009) Power Sharing. Peking University Press, Beijing.

[3] Candeias, M. and Rilling, R. (2008) Crisis of Privatization-Return of the Public Sphere.

[4] Nelson. (1997) The Effects of Alcohol, Tobacco and Recreational Drug Use on the Risk of Non-Hodgkins Lymphoma Unrelated to HIV Infection: A Case-Control Study.

[5] Nelson. (1997) The Effects of Alcohol, Tobacco and Recreational Drug Use on the Risk of Non-Hodgkins Lymphoma Unrelated to HIV Infection: A Case-Control Study.

[6] Johnston, J.M. and Romzek, B.S. (1999) Contracting and Accountability in State Medicaid Reform: Rhetoric, Theories, and Reality. Public Administration Review, 59, 383-399. https://doi.org/10.2307/977422

[7] Warner, M. and Hebdon, R. (2001) Local Government Restructuring: Privatization and Its Alternatives. Journal of Policy Analysis \& Management, 20, 315-336.

https://doi.org/10.1002/pam.2027

[8] Denhardt, R.B. and Denhardt, J.V. (2000) The New Public Service: Serving Rather than Steering. Public Administration Review, 60, 549-559. 
https://doi.org/10.1111/0033-3352.00117

[9] Blom-Hansen, J. (2003) Is Private Delivery of Public Services Really Cheaper? Evidence from Public Road Maintenance in Denmark. Public Choice, 115, 419-438. https://doi.org/10.1023/A:1024274527502

[10] Hefetz, A. and Warner, M. (2004) Privatization and Its Reverse: Explaining the Dynamics of the Government Contracting Process. Journal of Public Administration Research and Theory. J-PART, 14, 171-190. https://doi.org/10.1093/jopart/muh012

[11] Cooper, P. (2007) Contract Governance: Challenges and Opportunities for Public Managers. Fudan University Press, Shanghai.

[12] Bel, G. and Warner, M. (2008) Does Privatization of Solid Waste and Water Services Reduce Costs? A Review of Empirical Studies. Resources Conservation \& Recycling, 52, 1337-1348. https://doi.org/10.1016/j.resconrec.2008.07.014

[13] Goldsmith, S. and Kettl, D.F. (2009) Unlocking the Power of Networks: Keys to High-Performance Government. Brookings Institution Press and Ash Center for Democratic Governance and Innovation.

[14] Bel, G., Fageda, X. and Warner, M.E. (2009) Is Private Production of Public Services Cheaper than Public Production? A Meta-Regression Analysis of Solid Waste and Water Services. Journal of Policy Analysis \& Management, 29, 553-577. https://doi.org/10.1002/pam.20509

[15] Hefetz, A. and Warner, M.E. (2012) Contracting or Public Delivery? The Importance of Service, Market, and Management Characteristics. Journal of Public Administration Research \& Theory, 22, 289-317. https://doi.org/10.1093/jopart/mur006

[16] Mao, M. and Liu, Q. (2015) The Concept and Relationship of the Supply Mode of Public Service Cooperation in China. Journal of Industrial and Commercial University of Chongqing (Social Science Edition), No. 5, 44-51.

[17] Wang, C. (2015) Construction of Bottom Line and Analysis Framework of Government Purchase of Public Services. Journal of National School of Administration, No. 1, 69-73.

[18] Zhou, Y. (2015) The Existing Problems and Systems of Government Buying Public Services under the Context of Public and Private Cooperation and Improving the System of. Politics and Law, No. 12, 90-99.

[19] Xiang, X. (2015) Research on the Government Purchase of Public Service Boundary in China. China Administration, No. 6, 38-45.

[20] Ning, L. and Mao, J. (2015) An Empirical Study of the Government's Purchase of Public Services under Quasi Market Mechanism-Taking the Practice and Exploration of Minhang District, Shanghai as an Example. Journal of Ocean University of China (Social Science Edition), No. 4, 91-97.

[21] Zhan, G. (2013) Demand Side Defects, Supplier Defects and Smart Buyers-The Dilemma and Solution of Government Purchase of Public Service. Economic and Social System Comparison, No. 5, 142-150.

[22] Zhou, Y. and Cai, Y. (2016) The Operational Risk of the Purchase of Public Service Contract and Its Prevention Strategy. Administrative Forum, 23, 46-51.

[23] Chen, W.L. (2014) The Operation Mechanism, Strategy and Logic of Government and Non-Profit Organizations, a Sociological Analysis of the Government's Purchase of Social Work Services. Journal of Public Administration, No. 3, 93-105.

[24] Zou, Y. (2017) Government Purchase of Public Service Transfer and Acceptance-Based on the Practical Logic. Learning and Exploration of the Jiangxi Public 
Service Venture, No. 5, 51-57.

[25] Yu, J. (2016) The Government Procurement of Public Services from Social Organizations Risk Management-Based on the Principal-Agent Perspective and Beyond. Marx's Doctrine and Reality, No. 3, 169-175.

[26] Xu, J. and Xu, Y. (2015) Government Purchase of Social Organization Public Service System Risk Factors and Risk Management. Social Science Edition, No. 5, 45-49.

[27] Furubotn, E.G., Richter, R. and Jiang, X. (2006) New Institutional Economics: A Transaction Cost Analysis Paradigm. Shanghai People's Press, Shanghai.

[28] Dang, X. (2013) Rebuild Social Trust: The Spiritual Journey of China's Social Construction. China Administration, No. 7, 60-65.

[29] Ma, J. (2013) Multiple Philanthropic Cooperation and Its Legal Regulation. Jiangxi Social Sciences, No. 9, 148-153.

[30] Liu, X. (2008) Mechanism Analysis and Preventive Measures of Government Procurement Corruption. China Circulation Economy, 22, 8-11.

[31] Lv, S. (2012) Government Decentralization and Civil Relay. The People's Daily.

[32] Zhang, M. (2015) Administration Guarantee Liability after Government Purchase of Public Services. Administrative Forum, No. 5, 64-68.

[33] Xiang, X. (2012) Research on the Setting up of Government Purchasing Public Service Management Organization. Journal of Fujian Provincial Party School of CPC, No. 3, 41-47.

[34] Guy, P. (2001) Government's Future Governance Model. People's University Press, Beijing.

[35] Cai, W. (1997) Extension Engineering Method. Science Press, Beijing. 